\title{
Analyzing Integrated Cost-Schedule Risk for Complex Product Systems R\&D Projects
}

\author{
Zhe Xu, Jing Yu, and Hongbo Li \\ School of Economics and Management, Beihang University, 37 Xueyuan Road, Beijing 100191, China \\ Correspondence should be addressed to Jing Yu; yujingbuaa@163.com
}

Received 24 December 2013; Revised 1 June 2014; Accepted 2 June 2014; Published 24 June 2014

Academic Editor: Frank Werner

Copyright (C) 2014 Zhe Xu et al. This is an open access article distributed under the Creative Commons Attribution License, which permits unrestricted use, distribution, and reproduction in any medium, provided the original work is properly cited.

\begin{abstract}
The vast majority of the research efforts in project risk management tend to assess cost risk and schedule risk independently. However, project cost and time are related in reality and the relationship between them should be analyzed directly. We propose an integrated cost and schedule risk assessment model for complex product systems R\&D projects. Graphical evaluation review technique (GERT), Monte Carlo simulation, and probability distribution theory are utilized to establish the model. In addition, statistical analysis and regression analysis techniques are employed to analyze simulation outputs. Finally, a complex product systems R\&D project as an example is modeled by the proposed approach and the simulation outputs are analyzed to illustrate the effectiveness of the risk assessment model. It seems that integrating cost and schedule risk assessment can provide more reliable risk estimation results.
\end{abstract}

\section{Introduction}

Complex product systems can be defined as high cost, engineering-intensive products, systems, networks, and constructs [1]. Over the past two decades, the importance of complex product systems has been recognized and investigated by researchers (e.g., [2,3]). Risk assessment of cost and schedule, which plays an important role in complex product systems $\mathrm{R} \& \mathrm{D}$ project management, is concerned and studied closely [4].

The traditional approach to estimating risk of cost and schedule has been to estimate them independently (e.g., $[5,6])$. However, a number of limitations of independent estimation are pointed out by researchers. For example, $\mathrm{Xu}$ et al. [7] set up the estimation models of cost risk, schedule risk, and integrated risk, which show that the integrated risk probability estimation is different from independent estimaation. Additionally, Isidore and Back [8] verified that choosing a schedule value having a high confidence level does not guarantee that the associated cost estimate, corresponding to the selected schedule value, will also have a comparably high level of confidence, and vice versa. Hence, it is valuable to study the integrated risk.
In recent years, many approaches have been proposed to carry out relative research into integrated analysis problems of stochastic cost and schedule. Carr [9] presented equations which described parallel hierarchical cost and schedule control systems that calculate cost, schedule, and time variances at different levels of detail. Lee and Yi [10] utilized matrix analysis method which integrated the data of cost and duration in the form of matrix to study project integrated plan. Sen et al. [11] proposed an integrated probabilistic risk analysis for systems with multiple state variables. Robert and Randal [12] discussed a technique for integrating the uncertainties associated with cost and schedule when using the Monte Carlo simulation tool. A method to study integrated optimization plan of cost and schedule with a higher confidence level by using activity based costing simulation and multiple-simulation analysis technique was presented by Isidore and Back [13, 14]. Xu et al. [15] proposed an integrated confidence regression model of cost and schedule with Monte Carlo multiple simulation and regression analysis method. Poh and Tah [16] modeled risk impacts with integrated cost and schedule influence network for the construction project. Seyedhoseini et al. [17] introduced an integrated methodology with regard to time, 
quality, and cost which performed the project risk analysis in an effective manner. Furthermore, many other researchers discussed the techniques for analysis of risk to schedule and cost (e.g., [18-21]).

$\mathrm{Xu}$ et al. [7] first introduced the concept of integrated cost and schedule risk as the risk of failing to achieve the projects under a certain cost objective $\left(C^{*}\right)$ and schedule plan $\left(T^{*}\right)$. More exactly, it is expressed as an integrated bivariate probability distribution function of cost and schedule:

$$
R\left(C^{*}, T^{*}\right)=P\left(C>C^{*}, T>T^{*}\right) .
$$

They also take advantage of frequency statistical analysis method to model integrated risk probability estimation with Monte Carlo simulation.

In complex product systems R\&D project, rework of an activity is common, which is usually caused by probabilistic failure to meet the planned design objective. GERT considered such failure probability of activities and could be used to model and analyze the process of complex product systems with Monte Carlo simulation [22, 23]. Taylor and Moore [24] studied R\&D project planning with Q-GERT network modeling and simulation. In their research, a failure probability is given to each activity, and this activity can be fed back to its previous stage to be reworked.

In the paper, motivated by the successful use of the GERT, we employ this technique with multifeedback branches to describe the process of complex systems R\&D project. On the basis of the theory of probability and the relationship of marginal probability distribution function, conditional probability distribution function, and integrated probability distribution function, we construct an integrated cost and schedule risk estimation model. Finally, an example of a reallife project is analyzed with the integrated risk estimation model in detail. Compared with the prediction estimation using approximate curve surface, our method can estimate risk probability more rapidly and accurately by processing Monte Carlo simulation results.

The remainder of this paper is organized as follows. Section 2 describes the independent cost and schedule risk estimation model. Section 3 presents the integrated cost and schedule risk estimation model. An application of the model to a real-life project example is given in Section 4. Finally, Section 5 concludes the paper.

\section{Independent Cost and Schedule Risk Estimation}

Suppose that the simulation runs $k$ times, $k=1, \ldots, N$, and the simulation output results for total cost $C$ and total duration $T$ are $C^{(1)}, C^{(2)}, \ldots, C^{(N)}$ and $T^{(1)}, T^{(2)}, \ldots, T^{(N)}$, respectively. Utilizing frequency statistical analysis method, the output results are divided into the following intervals as $\left[C_{1}, C_{2}\right), \ldots,\left[C_{i}, C_{i+1}\right), \ldots,\left[C_{m}, C_{m+1}\right]$ and $\left[T_{1}, T_{2}\right), \ldots,\left[T_{j}, T_{j+1}\right), \ldots,\left[T_{l}, T_{l+1}\right]$. Then, we can count the frequency for each interval.

Let $a_{i}$. be the frequency of the cost interval $\left[C_{i}, C_{i+1}\right)$ and let $a_{. j}$ be that of the duration interval $\left[T_{j}, T_{j+1}\right)$. Thus,

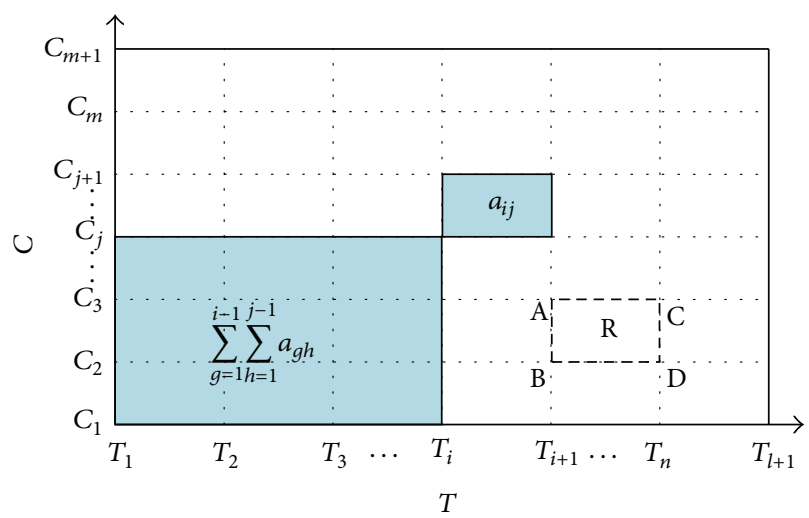

FIGURE 1: The integrated cost and schedule frequency statistics.

the marginal probability density functions of cost and schedule are defined as

$$
f\left(C_{i}\right)=\frac{a_{i}}{n} ; \quad f\left(T_{j}\right)=\frac{a_{\cdot j}}{n} .
$$

As a result, the marginal cumulative probability distribution functions are

$$
\begin{aligned}
& F\left(C_{i}\right)=P\left(C \leq C_{i}\right)=\sum_{g=1}^{i-1} f\left(C_{g}\right)=\sum_{g=1}^{i-1} \frac{a_{g}}{n} ; \\
& F\left(T_{j}\right)=P\left(T \leq T_{j}\right)=\sum_{h=1}^{j-1} f\left(T_{h}\right)=\sum_{h=1}^{j-1} \frac{a_{\cdot h}}{n} .
\end{aligned}
$$

Accordingly, the independent risk probability distribution functions are

$$
\begin{aligned}
& R\left(C_{i}\right)=P\left(C>C_{i}\right)=1-F\left(C_{i}\right) \\
& R\left(T_{j}\right)=P\left(T>T_{j}\right)=1-F\left(T_{j}\right) .
\end{aligned}
$$

\section{Integrated Cost and Schedule Risk Estimation}

3.1. Integrated Risk Probability Estimation. The integrated cost and schedule risk is defined as the probability of failing to complete the project under a specified objective with respect to cost and schedule. The integrated cost and schedule frequency statistics is shown in Figure 1.

Let $a_{i j}$ be the frequency of the shadow region $\left[\begin{array}{cc}C_{i} & C_{i+1} \\ T_{j} & T_{j+1}\end{array}\right)$ in Figure 1 . Then the integrated cost and schedule probability density function is

$$
f\left(C_{i}, T_{j}\right)=\frac{a_{i j}}{n} .
$$
$\left[\begin{array}{cc}C_{1} & C_{i} \\ T_{1} & T_{j}\end{array}\right)$ is

The integrated probability distribution function in region

$$
\begin{aligned}
F\left(C_{i}, T_{j}\right) & =P\left(C \leq C_{i}, T \leq T_{j}\right) \\
& =\sum_{g=1}^{i-1} \sum_{h=1}^{j-1} f\left(C_{g}, T_{h}\right)=\sum_{g=1}^{i-1} \sum_{h=1}^{j-1} \frac{a_{g h}}{n},
\end{aligned}
$$




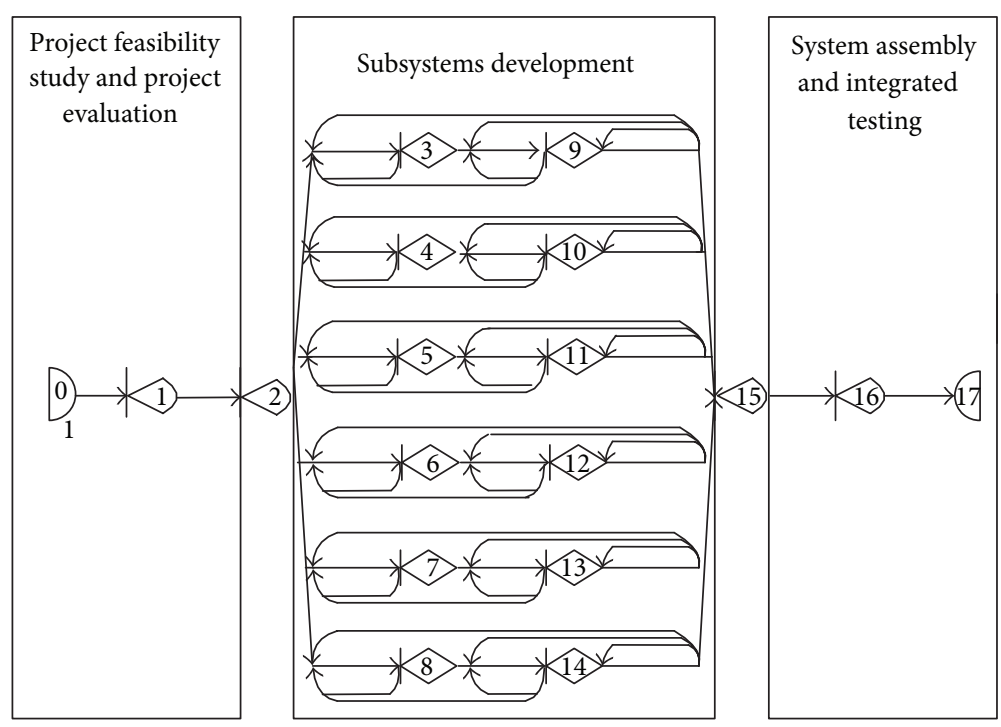

FIGURE 2: Stochastic multifeedback GERT model of the OCAV R\&D project.

where $\sum_{g=1}^{i-1} \sum_{h=1}^{j-1} a_{g h}$ is the cumulative frequency of simulation outputs which fall on the shadow region $\left[\begin{array}{cc}C_{1} & C_{i} \\ T_{1} & T_{j}\end{array}\right)$.

Accordingly, the integrated cost and schedule risk probability distribution function is

$$
R\left(C_{i}, T_{j}\right)=P\left(C>C_{i}, T>T_{j}\right)=1-F\left(C_{i}, T_{j}\right) .
$$

3.2. Conditional Risk Probability Estimation. $C$ and $T$ are components of two-dimensional random vector of cost and schedule, and on the condition that one $(C$ or $T)$ is assigned to a certain value, the probability density function of the other $(T$ or $C)$ is defined as conditional probability density function.

The conditional probability density functions of cost and schedule are

$$
\begin{aligned}
& f\left(\frac{C_{i}}{T_{j}}\right)=\frac{f\left(C_{i}, T_{j}\right)}{f\left(T_{j}\right)}=\frac{a_{i j} / n}{a_{\cdot j} / n}=\frac{a_{i j}}{a_{\cdot j}} ; \\
& f\left(\frac{T_{j}}{C_{i}}\right)=\frac{f\left(C_{i}, T_{j}\right)}{f\left(C_{i}\right)}=\frac{a_{i j} / n}{a_{i} / n}=\frac{a_{i j}}{a_{i} .}
\end{aligned}
$$

The conditional probability distribution functions of cost and schedule are

$$
\begin{aligned}
F\left(\frac{C_{i}}{T_{j}}\right) & =P\left(\frac{C \leq C_{i}}{T \leq T_{j}}\right) \\
& =\sum_{g=1}^{i-1} \sum_{h=1}^{j-1} \frac{a_{g h}}{a_{\cdot h}}=\frac{\sum_{g=1}^{i-1} \sum_{h=1}^{j-1} a_{g h}}{\sum_{h=1}^{j-1} a_{h}}=\frac{F\left(C_{i}, T_{j}\right)}{F\left(T_{j}\right)},
\end{aligned}
$$

$$
\begin{aligned}
F\left(\frac{T_{j}}{C_{i}}\right) & =P\left(\frac{T \leq T_{j}}{C \leq C_{i}}\right) \\
& =\sum_{g=1}^{i-1} \sum_{h=1}^{j-1} \frac{a_{g h}}{a_{g .}}=\frac{\sum_{g=1}^{i-1} \sum_{h=1}^{j-1} a_{g h}}{\sum_{g=1}^{i-1} a_{g}}=\frac{F\left(C_{i}, T_{j}\right)}{F\left(C_{i}\right)} .
\end{aligned}
$$

\section{Application Research}

4.1. GERT-Based Model. Our integrated cost and schedule risk estimation model is demonstrated with example data from an obstacle clearance armored vehicle (OCAV) R\&D project. We utilize GERT to model the OCAV R\&D process, which is usually divided into five phases: project feasibility study, project evaluation, subsystems development, system assembly, and integrated testing. The OCAV is composed of six subsystems. To focus on the simulation-based method presented in this paper, we name the six subsystems as subsystems 1 to 6 instead of their actual names.

Figure 2 shows a stochastic multifeedback GERT model of the OCAV R\&D project. In this model, we assume that the parameters of duration and cost are random variables and both of them follow the triangular distribution: $\operatorname{TRIA}(a, m, b)$ (as shown in Table 1), where $a$ is the best-case estimate, $m$ is the most likely estimate, and $b$ is the worst-case estimate. The parameters are estimated by project managers in a subjective manner or assessed through historical data.

4.2. Statistical Analysis of Simulation Output. Simulation runs $n=1000$ times. From the simulation output, we can get 1000 pairs of data of total cost and duration $\left(C_{k}, T_{k}\right)$, $k=1,2, \ldots, 1000$. Using frequency statistical method, the simulation outputs are grouped as $[0,5300),[5300,5600)$, $\ldots,[10700,11000]$ and $[0,53),[53,56), \ldots,[107,110]$, respectively. According to statistics, we obtain the marginal 
TABLE 1: Distribution of time and cost for the activities.

\begin{tabular}{|c|c|c|c|c|c|c|c|}
\hline \multirow{2}{*}{ Activities } & \multirow{2}{*}{ Number } & \multicolumn{3}{|c|}{ Time (month) } & \multicolumn{3}{|c|}{ Cost (million) } \\
\hline & & $a$ & $m$ & $b$ & $a$ & $m$ & $b$ \\
\hline Project feasibility studies & $0 \rightarrow 1$ & 6 & 9 & 12 & 0.50 & 1.00 & 1.50 \\
\hline Program demonstration & $1 \rightarrow 2$ & 3 & 6 & 9 & 6.00 & 6.50 & 7.00 \\
\hline \multirow{3}{*}{ Subsystem 1 development } & $2 \rightarrow 3$ & 2 & 3 & 4 & 0.20 & 0.30 & 0.40 \\
\hline & $3 \rightarrow 9$ & 12 & 14 & 16 & 9.00 & 11.00 & 13.00 \\
\hline & $9 \rightarrow 15$ & 10 & 12 & 12 & 1.80 & 2.00 & 2.20 \\
\hline \multirow{3}{*}{ Subsystem 2 development } & $2 \rightarrow 4$ & 1 & 2 & 3 & 0.05 & 0.10 & 0.15 \\
\hline & $4 \rightarrow 10$ & 10 & 12 & 14 & 6.00 & 8.00 & 10.00 \\
\hline & $10 \rightarrow 15$ & 10 & 12 & 12 & 2.00 & 3.00 & 4.00 \\
\hline \multirow{3}{*}{ Subsystem 3 development } & $2 \rightarrow 5$ & 2 & 3 & 4 & 0.15 & 0.20 & 0.25 \\
\hline & $5 \rightarrow 11$ & 10 & 12 & 14 & 5.00 & 7.00 & 9.00 \\
\hline & $11 \rightarrow 15$ & 10 & 12 & 12 & 2.00 & 3.00 & 4.00 \\
\hline \multirow{3}{*}{ Subsystem 4 development } & $2 \rightarrow 6$ & 1 & 2 & 3 & 0.05 & 0.10 & 0.15 \\
\hline & $6 \rightarrow 12$ & 8 & 10 & 12 & 1.30 & 1.50 & 1.70 \\
\hline & $12 \rightarrow 15$ & 6 & 10 & 12 & 0.20 & 0.30 & 0.40 \\
\hline \multirow{3}{*}{ Subsystem 5 development } & $2 \rightarrow 7$ & 1 & 2 & 3 & 0.05 & 0.10 & 0.15 \\
\hline & $7 \rightarrow 13$ & 6 & 8 & 10 & 0.90 & 1.00 & 1.00 \\
\hline & $13 \rightarrow 15$ & 8 & 10 & 12 & 0.10 & 0.20 & 0.30 \\
\hline \multirow{3}{*}{ Subsystem 6 development } & $2 \rightarrow 8$ & 1 & 2 & 3 & 0.05 & 0.10 & 0.10 \\
\hline & $8 \rightarrow 14$ & 10 & 12 & 14 & 0.60 & 0.80 & 1.00 \\
\hline & $14 \rightarrow 15$ & 10 & 12 & 12 & 0.10 & 0.20 & 0.30 \\
\hline System assembly & $15 \rightarrow 16$ & 2 & 4 & 6 & 0.30 & 0.40 & 0.50 \\
\hline Integrated testing & $16 \rightarrow 17$ & 9 & 12 & 15 & 800 & 1000 & 1200 \\
\hline
\end{tabular}

TABLE 2: The integrated and marginal frequency distribution of total cost and duration.

\begin{tabular}{|c|c|c|c|c|c|c|c|c|c|c|}
\hline \multirow{2}{*}{$C_{i}$} & \multicolumn{10}{|c|}{$T_{j}$} \\
\hline & $0 \sim 53$ & $53 \sim 56$ & $56 \sim 59$ & $\cdots$ & $74 \sim 77$ & $77 \sim 80$ & $\cdots$ & $104 \sim 107$ & $107 \sim 110$ & $a_{j}$ \\
\hline $0 \sim 5300$ & 0 & 0 & 0 & $\cdots$ & 0 & 0 & $\cdots$ & 0 & 0 & 1 \\
\hline $5300 \sim 5600$ & 0 & 1 & 0 & $\ldots$ & 0 & 0 & $\ldots$ & 0 & 0 & 5 \\
\hline $5600 \sim 5900$ & 0 & 0 & 0 & $\cdots$ & 4 & 1 & $\cdots$ & 0 & 0 & 26 \\
\hline$\cdots$ & $\cdots$ & $\cdots$ & $\cdots$ & $\cdots$ & $\cdots$ & $\cdots$ & $\cdots$ & $\cdots$ & $\cdots$ & $\cdots$ \\
\hline 7400 7700 & 0 & 0 & 0 & $\ldots$ & 10 & 17 & $\ldots$ & 0 & 0 & 109 \\
\hline $7700 \sim 8000$ & 0 & 0 & 0 & $\cdots$ & 5 & 11 & $\cdots$ & 2 & 0 & 122 \\
\hline$\cdots$ & $\cdots$ & $\cdots$ & $\cdots$ & $\cdots$ & $\cdots$ & $\cdots$ & $\cdots$ & $\cdots$ & $\ldots$ & $\ldots$ \\
\hline $10400 \sim 10700$ & 0 & 0 & 0 & $\cdots$ & 0 & 0 & $\cdots$ & 0 & 0 & 3 \\
\hline $10700 \sim 11000$ & 0 & 0 & 0 & $\cdots$ & 0 & 0 & $\cdots$ & 0 & 0 & 1 \\
\hline$a_{i}$ & $\mathbf{0}$ & 1 & $\mathbf{0}$ & $\cdots$ & 86 & 130 & $\cdots$ & 7 & 1 & 1000 \\
\hline
\end{tabular}

frequency distribution of total cost $a_{i}$, the marginal frequency distribution of total duration $a_{j}$, and the integrated bivariate frequency distribution $a_{i j}$, and the results are shown in Table 2.

We can also obtain the following results.

(1) According to the simulation results, the mean and standard deviations of the total cost and duration are calculated as follows:

$$
\begin{gathered}
\widehat{\mu}_{C} \approx \bar{C}=\frac{1}{n} \sum_{k=1}^{n} C_{k}=7477.0880 ; \\
\widehat{\sigma}_{c} \approx s_{C}=\sqrt{\sum_{k=1}^{n} \frac{\left(C_{k}-\bar{C}\right)^{2}}{n-1}}=927.1721
\end{gathered}
$$

$$
\begin{gathered}
\widehat{\mu}_{T} \approx \bar{T}=\frac{1}{n} \sum_{k=1}^{n} T_{k}=83.3316 ; \\
\widehat{\sigma}_{T} \approx s_{T}=\sqrt{\sum_{k=1}^{n} \frac{\left(T_{k}-\bar{T}\right)^{2}}{n-1}}=8.2054 .
\end{gathered}
$$

(2) Frequency histograms of total cost and duration can be drawn and are shown in Figures 3 and 4.

(3) We perform the goodness of fit test and deduce that the probability distribution of the total cost and duration is normal distribution. More specifically, the theoretical probability distribution functions of 


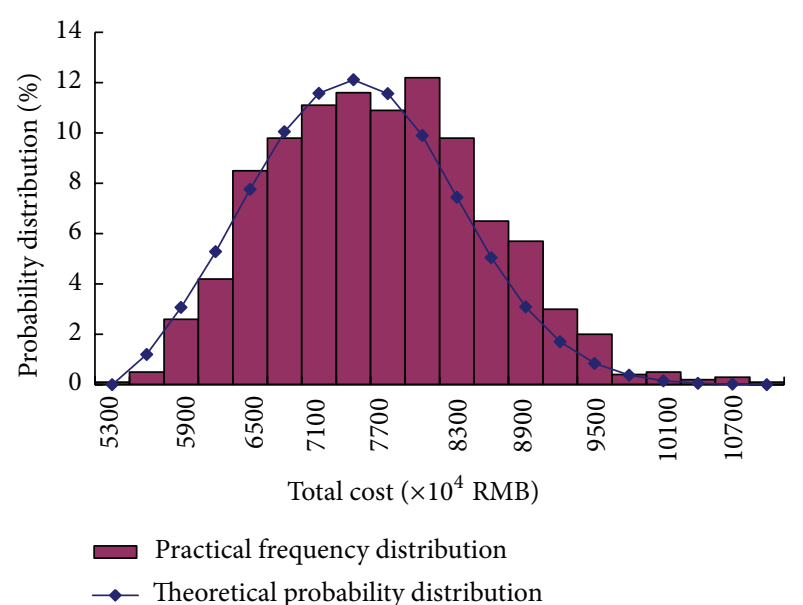

FIGURE 3: The frequency histograms and probability distribution of total cost.

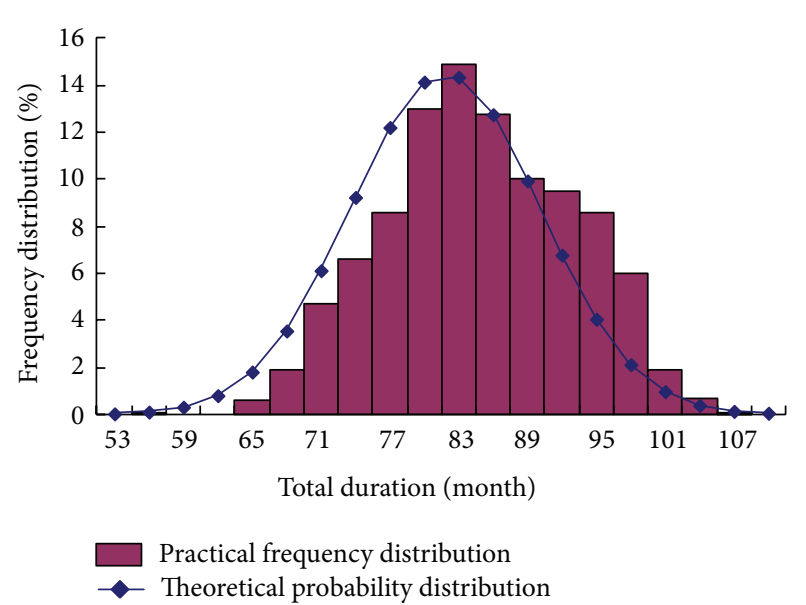

FIGURE 4: The frequency histograms and probability distribution of total duration.

the total cost and duration are subject to $N\left(\widehat{\mu}_{C}, \widehat{\sigma}_{C}^{2}\right)$ and $N\left(\widehat{\mu}_{T}, \widehat{\sigma}_{T}^{2}\right)$, respectively. Besides, the distribution curves are shown in Figures 3 and 4.

(4) From the result in (3), we believe that the total cost and duration are all subject to normal distribution. Hence, interval estimation of parameter can be carried out.

The confidence interval of $95 \%$ for the total cost $C$ is

$$
\left(\widehat{\mu}_{C}-z_{\alpha / 2} \frac{\widehat{\sigma}_{C}}{\sqrt{n}}, \widehat{\mu}_{C}+z_{\alpha / 2} \frac{\widehat{\sigma}_{C}}{\sqrt{n}}\right)
$$

$=(7419.6213,7534.5547)$ Ten thousand RMB.

The confidence interval of $95 \%$ for the total duration $T$ is

$$
\begin{aligned}
\left(\widehat{\mu}_{T}\right. & \left.-z_{\alpha / 2} \frac{\widehat{\sigma}_{T}}{\sqrt{n}}, \widehat{\mu}_{T}+z_{\alpha / 2} \frac{\widehat{\sigma}_{T}}{\sqrt{n}}\right) \\
& =(82.8230,83.8401) \text { Months. }
\end{aligned}
$$

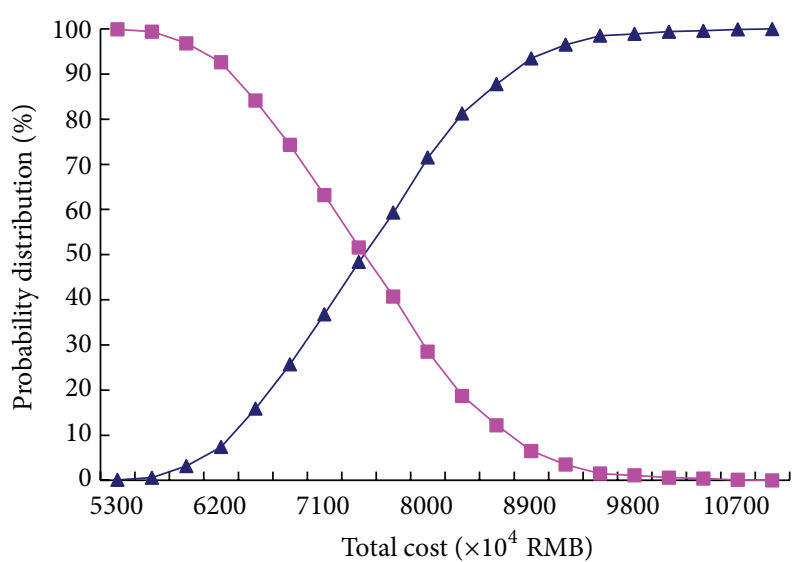

FIGURE 5: The marginal probability distribution and marginal risk probability distribution of total cost.

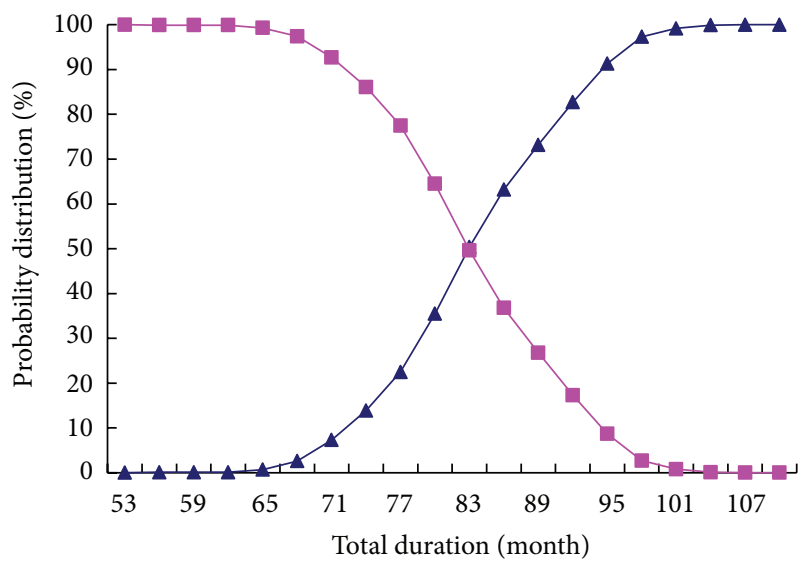

FIGURE 6: The marginal probability distribution and marginal risk probability distribution of total duration.

4.3. Independent Estimation of Risk. We can get the marginal probability density functions of the total cost and total duration $f\left(C_{i}\right)$ and $f\left(T_{i}\right)$, the marginal probability distribution functions $F\left(C_{i}\right)$ and $F\left(T_{i}\right)$, and the marginal risk probability distribution functions $R\left(C_{i}\right)$ and $R\left(T_{i}\right)$ by substituting data into formulas (1)-(3); all the results are shown in Table 3.

The marginal probability distribution and the marginal risk probability distribution of the total cost and the total duration are shown in Figures 5 and 6, respectively.

4.4. Integrated Estimation of Risk. According to formulas (6) and (7), we can get the integrated probability distribution of the total cost and duration $F\left(C_{i}, T_{i}\right)$ in Table 4 and the integrated risk probability distribution of total cost and duration $R\left(C_{i}, T_{i}\right)$ in Table 5.

According to the data in Table 5, we draw the curved surface of integrated risk probability distribution of total cost and duration in Figure 7.

4.5. Conditional Estimation of Risk. According to formula (9), we can get the conditional probability density distributions 
TABLE 3: Marginal risk probability distribution of total cost and duration.

\begin{tabular}{lccccccc}
\hline Total cost $C_{i}$ & $f\left(C_{i}\right)$ & $F\left(C_{i}\right)$ & $R\left(C_{i}\right)$ & Total duration $T_{j}$ & $f\left(T_{j}\right)$ & $F\left(T_{j}\right)$ \\
\hline 53 & 0.001 & 0.001 & 0.999 & 53 & 0.000 & 0.000 \\
56 & 0.005 & 0.006 & 0.994 & 56 & 0.001 & 0.001 \\
$\ldots$ & $\ldots$ & $\ldots$ & $\ldots$ & $\ldots$ & $\ldots$ & 0.999 \\
77 & 0.109 & 0.593 & 0.407 & 77 & 0.086 & 0.225 \\
80 & 0.122 & 0.715 & 0.285 & 80 & 0.130 & 0.355 \\
$\ldots$ & $\ldots$ & $\ldots$ & $\ldots$ & $\ldots$ & $\ldots$ & 0.775 \\
107 & 0.003 & 0.999 & 0.001 & 107 & 0.001 & $\ldots$ \\
110 & 0.001 & 1.000 & 0.000 & 110 & 0.000 & 1.000 \\
\end{tabular}

TABLE 4: Integrated probability distribution of total cost and duration $F\left(C_{i}, T_{i}\right)$.

\begin{tabular}{|c|c|c|c|c|c|c|c|c|}
\hline \multirow{2}{*}{ Total cost $C_{i}$} & \multicolumn{8}{|c|}{ Total duration $T_{j}$} \\
\hline & 53 & 56 & $\cdots$ & 74 & 77 & $\cdots$ & 107 & 110 \\
\hline 5300 & 0.000 & 0.000 & $\cdots$ & 0.000 & 0.000 & $\cdots$ & 0.001 & 0.001 \\
\hline 5600 & 0.000 & 0.001 & $\cdots$ & 0.003 & 0.003 & $\cdots$ & 0.006 & 0.006 \\
\hline$\cdots$ & $\cdots$ & $\cdots$ & $\cdots$ & $\cdots$ & $\cdots$ & $\cdots$ & $\cdots$ & $\cdots$ \\
\hline 7700 & 0.000 & 0.001 & $\cdots$ & 0.135 & 0.210 & $\cdots$ & 0.593 & 0.593 \\
\hline 8000 & 0.000 & 0.001 & $\cdots$ & 0.139 & 0.219 & $\cdots$ & 0.715 & 0.715 \\
\hline$\cdots$ & $\cdots$ & $\cdots$ & $\cdots$ & $\cdots$ & $\cdots$ & $\cdots$ & $\cdots$ & $\cdots$ \\
\hline 10700 & 0.000 & 0.001 & $\cdots$ & 0.139 & 0.225 & $\cdots$ & 0.999 & 0.999 \\
\hline 11000 & 0.000 & 0.001 & $\cdots$ & 0.139 & 0.225 & $\cdots$ & 1.000 & 1.000 \\
\hline
\end{tabular}

TABLE 5: Integrated risk probability distribution of total cost and duration $R\left(C_{i}, T_{i}\right)$.

\begin{tabular}{|c|c|c|c|c|c|c|c|c|}
\hline \multirow{2}{*}{ Total cost $C_{i}$} & \multicolumn{8}{|c|}{ Total duration $T_{j}$} \\
\hline & 53 & 56 & $\cdots$ & 74 & 77 & $\cdots$ & 107 & 110 \\
\hline 5300 & 1.000 & 1.000 & $\cdots$ & 1.000 & 1.000 & $\cdots$ & 0.999 & 0.999 \\
\hline 5600 & 1.000 & 0.999 & $\cdots$ & 0.997 & 0.997 & $\cdots$ & 0.994 & 0.994 \\
\hline$\cdots$ & $\cdots$ & $\cdots$ & $\cdots$ & $\cdots$ & $\cdots$ & $\cdots$ & $\cdots$ & $\cdots$ \\
\hline 7700 & 1.000 & 0.999 & $\cdots$ & 0.865 & 0.790 & $\cdots$ & 0.407 & 0.407 \\
\hline 8000 & 1.000 & 0.999 & $\cdots$ & 0.861 & 0.781 & $\cdots$ & 0.285 & 0.285 \\
\hline$\cdots$ & $\cdots$ & $\cdots$ & $\cdots$ & $\cdots$ & $\cdots$ & $\cdots$ & $\cdots$ & $\cdots$ \\
\hline 10700 & 1.000 & 0.999 & $\cdots$ & 0.861 & 0.775 & $\cdots$ & 0.001 & 0.001 \\
\hline 11000 & 1.000 & 0.999 & $\cdots$ & 0.861 & 0.775 & $\cdots$ & 0.000 & 0.000 \\
\hline
\end{tabular}

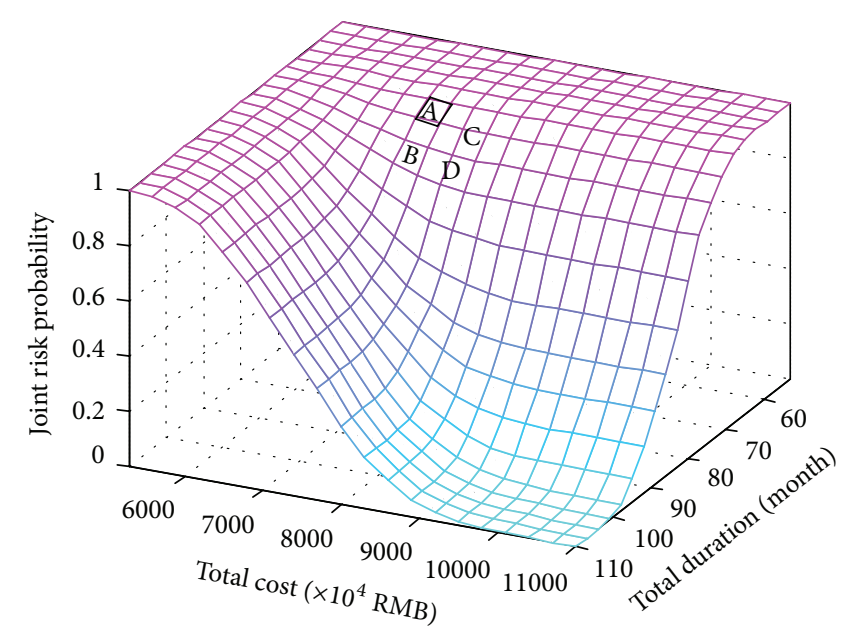

FIGURE 7: Curved surface of integrated risk probability distribution of total cost and duration. 
TABLE 6: Conditional probability distribution of the total cost $F\left(C_{i} / T_{j}\right)$.

\begin{tabular}{|c|c|c|c|c|c|c|c|c|}
\hline \multirow{2}{*}{ Total cost $C_{i}$} & \multicolumn{8}{|c|}{ Total duration $T_{j}$} \\
\hline & 53 & 56 & $\cdots$ & 74 & 77 & $\cdots$ & 107 & 110 \\
\hline 5300 & 0.000 & 0.000 & $\cdots$ & 0.000 & 0.000 & $\cdots$ & 0.001 & 0.001 \\
\hline 5600 & 0.000 & 1.000 & $\cdots$ & 0.022 & 0.013 & $\cdots$ & 0.006 & 0.006 \\
\hline$\cdots$ & $\cdots$ & $\cdots$ & $\cdots$ & $\cdots$ & $\cdots$ & $\cdots$ & $\cdots$ & $\cdots$ \\
\hline 7700 & 0.000 & 1.000 & $\cdots$ & 0.971 & 0.933 & $\cdots$ & 0.593 & 0.593 \\
\hline 8000 & 0.000 & 1.000 & $\cdots$ & 1.000 & 0.973 & $\ldots$ & 0.715 & 0.715 \\
\hline$\cdots$ & $\cdots$ & $\cdots$ & $\cdots$ & $\cdots$ & $\cdots$ & $\cdots$ & $\cdots$ & $\cdots$ \\
\hline 10700 & 0.000 & 1.000 & $\cdots$ & 1.000 & 1.000 & $\cdots$ & 0.999 & 0.999 \\
\hline 11000 & 0.000 & 1.000 & $\cdots$ & 1.000 & 1.000 & $\cdots$ & 1.000 & 1.000 \\
\hline
\end{tabular}

TABLE 7: Conditional probability distribution of the total duration $F\left(T_{j} / C_{i}\right)$.

\begin{tabular}{|c|c|c|c|c|c|c|c|c|}
\hline \multirow{2}{*}{ Total cost $C_{i}$} & \multicolumn{8}{|c|}{ Total duration $T_{j}$} \\
\hline & 53 & 56 & $\ldots$ & 74 & 77 & $\ldots$ & 107 & 110 \\
\hline 5300 & 0.000 & 0.000 & $\cdots$ & 0.000 & 0.000 & $\cdots$ & 0.000 & 0.000 \\
\hline 5600 & 0.000 & 0.167 & $\cdots$ & 0.002 & 0.002 & $\cdots$ & 0.001 & 0.001 \\
\hline$\cdots$ & $\cdots$ & $\cdots$ & $\cdots$ & $\cdots$ & $\cdots$ & $\cdots$ & $\cdots$ & $\cdots$ \\
\hline 7700 & 0.000 & 0.500 & $\cdots$ & 0.388 & 0.354 & $\cdots$ & 0.139 & 0.139 \\
\hline 8000 & 0.000 & 0.500 & $\ldots$ & 0.556 & 0.519 & $\cdots$ & 0.225 & 0.225 \\
\hline$\cdots$ & $\cdots$ & $\cdots$ & $\cdots$ & $\cdots$ & $\cdots$ & $\cdots$ & $\cdots$ & $\cdots$ \\
\hline 10700 & 1.000 & 1.000 & $\cdots$ & 1.000 & 1.000 & $\cdots$ & 1.000 & 1.000 \\
\hline 11000 & 1.000 & 1.000 & $\cdots$ & 1.000 & 1.000 & $\cdots$ & 1.000 & 1.000 \\
\hline
\end{tabular}

TABLE 8: Mean and standard deviation of conditional probability distribution of total cost and duration.

\begin{tabular}{|c|c|c|c|c|c|}
\hline $\begin{array}{l}\text { Conditional } \\
\text { distribution of total } \\
\text { duration }\end{array}$ & $\begin{array}{c}\text { Mean estimation } \\
\qquad \widehat{\mu}\end{array}$ & $\begin{array}{l}\text { Standard deviation } \\
\quad \text { estimation } \widehat{\sigma}\end{array}$ & $\begin{array}{c}\text { Conditional } \\
\text { distribution of total } \\
\text { cost }\end{array}$ & $\begin{array}{c}\text { Mean estimation } \\
\qquad \widehat{\mu}\end{array}$ & $\begin{array}{l}\text { Standard deviation } \\
\text { estimation } \widehat{\sigma}\end{array}$ \\
\hline$F(T / 5600)$ & 73.00 & 11.41 & $F(C / 56)$ & 5450.00 & 0.00 \\
\hline$F(T / 5900)$ & 73.06 & 6.47 & $F(C / 59)$ & 5450.00 & 0.00 \\
\hline$F(T / 6200)$ & 74.81 & 6.66 & $F(C / 62)$ & 5450.00 & 0.00 \\
\hline$\cdots$ & $\cdots$ & $\ldots$ & $\ldots$ & $\ldots$ & $\ldots$ \\
\hline$F(T / 7100)$ & 78.17 & 7.10 & $F(C / 71)$ & 6543.15 & 590.41 \\
\hline$F(T / 7400)$ & 79.16 & 7.30 & $F(C / 74)$ & 6587.41 & 596.18 \\
\hline$F(T / 7700)$ & 79.90 & 7.49 & $F(C / 77)$ & 6726.00 & 645.77 \\
\hline$F(T / 8000)$ & 81.12 & 7.93 & $F(C / 80)$ & 6900.14 & 705.49 \\
\hline$\cdots$ & $\cdots$ & $\cdots$ & $\cdots$ & $\cdots$ & $\cdots$ \\
\hline$F(T / 10400)$ & 83.25 & 8.24 & $F(C / 104)$ & 7476.43 & 929.64 \\
\hline$F(T / 10700)$ & 83.28 & 8.25 & $F(C / 107)$ & 7477.40 & 929.68 \\
\hline$F(T / 11000)$ & 83.30 & 8.26 & $F(C / 110)$ & 7477.40 & 929.68 \\
\hline
\end{tabular}

of the total cost and total duration $F\left(C_{i} / T_{j}\right)$ and $F\left(T_{j} / C_{i}\right)$ in Tables 6 and 7.

According to the above results, the smooth curves of conditional probability distribution of the total cost and the total duration are drawn in Figures 8 and 9.

Using goodness of fit test method, we infer that the conditional probability distributions of the total cost and the total duration follow normal distributions, and the goodness of fit is good. Meanwhile, the mean $\widehat{\mu}$ and the standard deviation $\widehat{\sigma}$ of the conditional probability distribution are obtained. The results are shown in Table 8; the computational process is similar to the following example:

$$
\begin{aligned}
F\left(\frac{C}{74}\right) & =1-\int_{0}^{C} \frac{1}{596.18 \sqrt{2 \pi}} e^{-(C-6587.41)^{2} /(2 \times 596.18)} \\
& =1-\Phi\left(\frac{C-6587.41}{596.18}\right)
\end{aligned}
$$




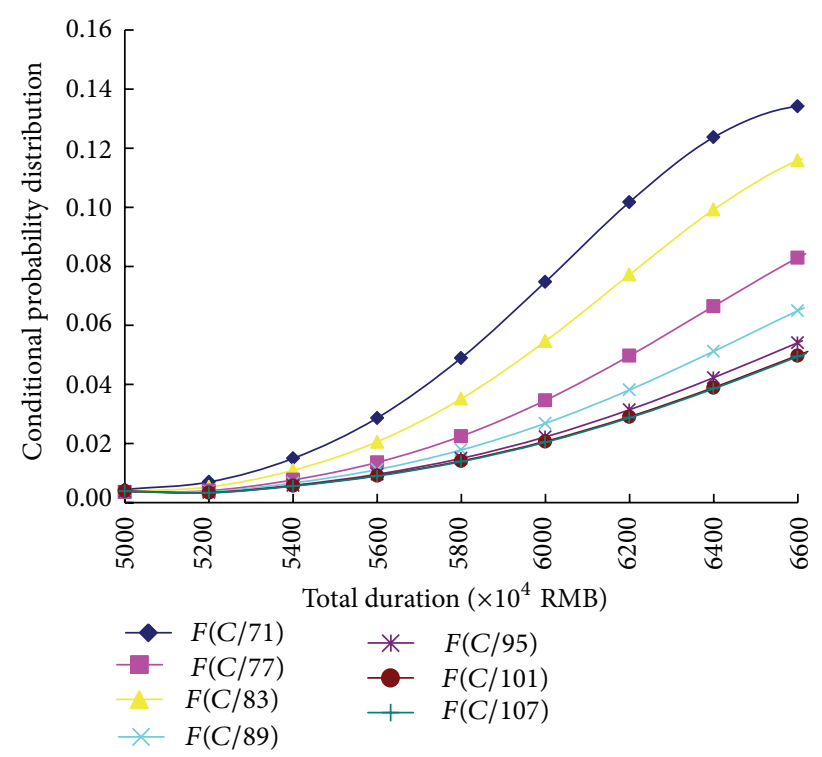

FIgURE 8: Conditional probability distribution $F\left(C_{i} / T_{j}\right)$ of the total cost (partly).

$$
\begin{aligned}
F\left(\frac{T}{7700}\right) & =1-\int_{0}^{C} \frac{1}{7.49 \sqrt{2 \pi}} e^{-(T-79.901)^{2} /(2 \times 7.49)} \\
& =1-\Phi\left(\frac{T-79.90}{7.49}\right)
\end{aligned}
$$

\subsection{Prediction Estimation of Integrated Risk Probability}

4.6.1. Prediction Estimation Based on Curved Surface of Integrated Risk Probability. Through the data in Table 5, we establish the integrated risk space surface of two-dimensional continuous random vector $(C, T)$ of the cost and duration. Also, we obtain the integrated risk probability approximation under cost and duration constraints by surface interpolation method. For example, $R(7800,75)$ is the risk probability value under constraints of the total cost $C \geq 7800$ ten thousand RMB and the total duration $T \geq 75$ months. In Figure 6, when the number of simulations is large enough, the small curved surface which consisted of $A(7700,74,0.865)$, $B(7700,77,0.790), C(8000,74,0.861)$, and $D(8000,77,0.781)$ can be considered as a plane. In order to avoid underestimating the probability value, we choose $A, B$, and $C$ which have higher risk probability to establish equation:

$$
\begin{aligned}
& \left|\begin{array}{ll}
T_{B}-T_{A} & R_{B}-R_{A} \\
T_{C}-T_{A} & R_{C}-R_{A}
\end{array}\right|\left(C-C_{A}\right) \\
& +\left|\begin{array}{ll}
R_{B}-R_{A} & C_{B}-C_{A} \\
R_{C}-R_{A} & C_{C}-C_{A}
\end{array}\right|\left(T-T_{A}\right) \\
& +\left|\begin{array}{ll}
C_{B}-C_{A} & T_{B}-T_{A} \\
C_{C}-C_{A} & T_{C}-T_{A}
\end{array}\right|\left(R-R_{A}\right)=0 .
\end{aligned}
$$

After that, the risk probability value $R$ is acquired under constraints of total cost $C$ and total duration $T$. We can substitute $A, B, C$ into (14) to gain $R(7800,75)=0.8387$.

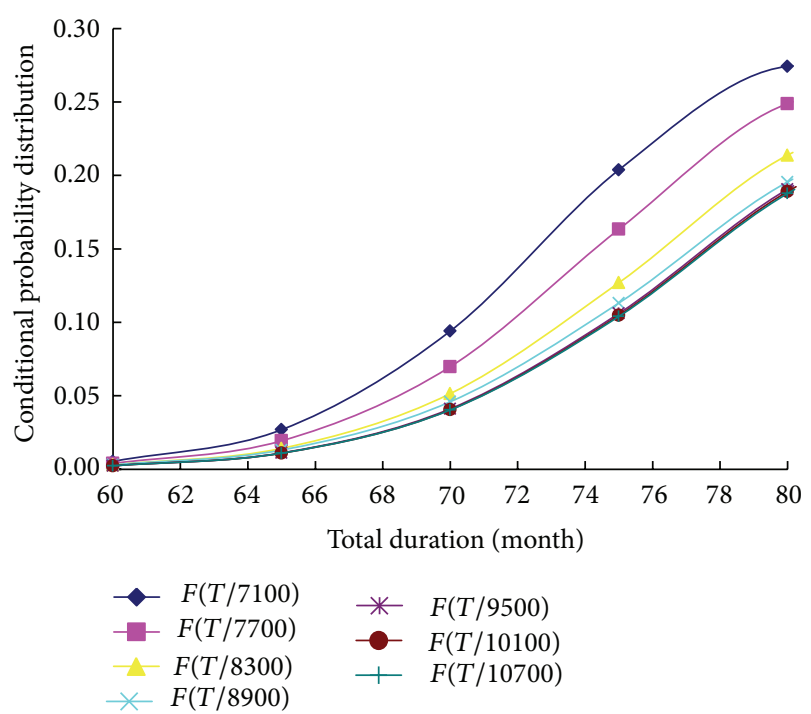

FIGURE 9: Conditional probability distribution $F\left(T_{j} / C_{i}\right)$ of the total duration (partly).

4.6.2. Prediction Estimation Based on Theory of Integrated Risk Probability Distribution. Following the definition of the conditional probability distribution function and the marginal probability distribution function, the integrated risk probability of the total cost and duration is calculated as follows:

$$
\begin{gathered}
F(C, T)=F\left(\frac{C}{T}\right) \times F(T) ; \\
F(T, C)=F\left(\frac{T}{C}\right) \times F(C) ; \\
R(C, T)=1-F(C, T) ; \\
R(T, C)=1-F(T, C) .
\end{gathered}
$$

For example, we also get the risk probability value $R(7800,75)$ under the integrated constraints of the total cost $C \geq 7800$ ten thousand RMB and the total duration $T \geq 75$ months. The specific calculation steps are as follows.

(1) With the data from Table 8 , the mean estimation and the standard variance estimation of the conditional distribution functions $F(C / 75)$ and $F(T / 7800)$ are determined by interpolation:

$$
\begin{aligned}
\widehat{\mu}_{(C / 75)}=6633.61 ; & \widehat{\mu}_{(T / 7800)} & =80.307 \\
\widehat{\sigma}_{(C / 75)}=612.71 ; & \widehat{\sigma}_{(T / 7800)} & =7.64 .
\end{aligned}
$$

(2) Calculate the conditional probability distribution values by normal distribution:

$$
\begin{aligned}
& F\left(\frac{7800}{75}\right)=\Phi\left(\frac{7800-6633.61}{612.71}\right)=\Phi(1.9043)=0.9716 \\
& F\left(\frac{75}{7800}\right)=\Phi\left(\frac{75-80.307}{7.64}\right)=\Phi(-0.6946)=0.2437
\end{aligned}
$$


(3) According to formula (3), the marginal probability distributions $F(7800)$ and $F(75)$ are obtained as

$$
F(7800)=0.634 ; \quad F(75)=0.168 .
$$

(4) Through formula (15), we calculate the values of the integrated probability distribution $F(7800,75)$ and $F(75,7800)$ and the integrated risk probability values $R(7800,75)$ and $R(75,7800)$; that is,

$$
\begin{gathered}
F(7800,75)=F\left(\frac{7800}{75}\right) \times F(75) \\
=0.9716 \times 0.1680=0.1632 . \\
R(7800,75)=1-F(7800,75)=1-0.1632=0.8368 \\
F(75,7800)=F\left(\frac{75}{7800}\right) \times F(7800) \\
=0.2437 \times 0.6340=0.1545 \\
R(75,7800)=1-F(75,7800)=1-0.1545=0.8455 .
\end{gathered}
$$

4.6.3. Error Analysis of Prediction. By analyzing the output data of 1000 times simulation, we can calculate the frequency of occurrence that the total cost $C \leq 7800$ ten thousand RMB and the total duration $T \leq 75$ months are 162. By formula (15), we get

$$
\begin{aligned}
& F(7800,75)=P(C \leq 7800, T \leq 75)=\frac{162}{1000}=0.1620 \\
& R(7800,75)=1-F(7800,75)=1-0.162=0.8380 .
\end{aligned}
$$

For purposes of comparison, we also report results based on the curved surface method of integrated risk probability. The prediction result is $R(7800,75)=0.8387$, and the relative error of prediction is $(|0.8387-0.838| / 0.838) \times$ $100 \%=0.0835 \%$. Meanwhile, based on the conditions of risk probability distribution functions proposed in this paper, we have (a) $R(7800,75)=0.8368$, where the relative error is $(|0.8368-0.838| / 0.838) \times 100 \%=0.143 \%$ and $(b)$ $R(75,7800)=0.8455$, where the relative error is $(\mid 0.8455-$ $0.838 \mid / 0.838) \times 100 \%=0.895 \%$.

The above comparison results of relative error reveal that both of the methods are practical. However, it is too complicated to build the equation when using the approximate curve surface method. And the method proposed in this paper can estimate risk probability more rapidly and accurately by processing one set of Monte Carlo simulation results.

\section{Conclusions}

Based on GERT multifeedback simulation and the theory of probability distribution, we have presented an integrated risk model of cost and schedule. Using statistical analysis and Monte Carlo techniques, we get the marginal probability distribution functions and the conditional probability distribution functions. Finally, the integrated probability distribution functions of cost and schedule and risk probability distribution function are obtained. This method is proven to be more accurate. However, we know that there are many other factors in complex product systems except cost and schedule, such as environment and project resources. In the future, we will study the risk assessment about more elements.

\section{Conflict of Interests}

The authors declare that there is no conflict of interests regarding the publication of this paper.

\section{Acknowledgments}

This research is supported by the Innovation Foundation of BUAA for Ph.D. Graduates and the National Science Foundation of China under Grant 71271019.

\section{References}

[1] Y. T. Ren and K. T. Yeo, "Research challenges on complex product systems (CoPS) innovation," Journal of the Chinese Institute of Industrial Engineers, vol. 23, no. 6, pp. 519-529, 2006.

[2] K. L. Hansen and H. Rush, "Hotspots in complex product systems: emerging issues in innovation management," Technovation, vol. 18, no. 8-9, pp. 555-561, 1998.

[3] M. Hobday, "Product complexity, innovation and industrial organisation," Research Policy, vol. 26, no. 6, pp. 689-710, 1998.

[4] M. G. Moehrle and L. Walter, "Risk and uncertainty in R\&D management," $R$ and D Management, vol. 38, no. 5, pp. 449-451, 2008.

[5] K. C. Crandall and J. C. Woolery, "Schedule development under stochastic scheduling," Journal of the Construction Division, vol. 108, no. 2, pp. 321-329, 1982.

[6] J. E. Diekmann, "Probabilistic estimating: mathematics and applications," Journal of Construction Engineering and Management, vol. 109, no. 3, pp. 297-308, 1983.

[7] Z. Xu, Y. Feng, and Y. Wei, "Cost-schedule risk estimation for engineering systems," Science Research Management, vol. 19, no. 6, pp. 38-43, 1998.

[8] L. J. Isidore and W. E. Back, "Multiple simulation analysis for probabilistic cost and schedule integration," Journal of Construction Engineering and Management, vol. 128, no. 3, pp. 211-219, 2002.

[9] R. I. Carr, "Cost, schedule, and time variances and integration," Journal of Construction Engineering and Management, vol. 119, no. 2, pp. 245-265, 1993.

[10] H. Lee and K. J. Yi, "Application of mathematical matrix to integrate project schedule and cost," Journal of Construction Engineering and Management, vol. 125, no. 5, pp. 339-346, 1999.

[11] P. Sen, J. K. G. Tan, and D. Spencer, "An integrated probabilistic risk analysis decision support methodology for systems with multiple state variables," Reliability Engineering and System Safety, vol. 64, no. 1, pp. 73-87, 1999.

[12] V. W. Robert and B. L. Randal, "Integration of schedule and cost risk models," Cost Engineering, vol. 42, no. 4, pp. 38-43, 2000. 
[13] L. J. Isidore and W. E. Back, "Integrated range estimation and stochastic schedule," Cost Engineering, vol. 43, no. 2, pp. 41-44, 2001.

[14] L. J. Isidore and W. E. Back, "Probabilistic optimal-cost scheduling," Journal of Construction Engineering and Management, vol. 127, no. 6, pp. 431-437, 2001.

[15] Z. Xu, J. Wu, and Y. Wang, "Confidence percentile estimation to cost and schedule integration based on Monte Carlo multiple simulation analysis technique," Journal of System Simulation, vol. 18, no. 12, pp. 3334-3337, 2006.

[16] Y. P. Poh and J. H. M. Tah, "Integrated duration-cost influence network for modelling risk impacts on construction tasks," Construction Management and Economics, vol. 24, no. 8, pp. 861-868, 2006.

[17] S. M. Seyedhoseini, S. Noori, and M. A. Hatefi, "An integrated methodology for assessment and selection of the project risk response actions," Risk Analysis, vol. 29, no. 5, pp. 752-763, 2009.

[18] G. A. Barraza, W. E. Back, and F. Mata, "Probabilistic monitoring of project performance using SS-curves," Journal of Construction Engineering and Management, vol. 126, no. 2, pp. 142-148, 2000.

[19] G. A. Barraza, W. E. Back, and F. Mata, "Probabilistic forecasting of project performance using stochastic S curves," Journal of Construction Engineering and Management, vol. 130, no. 1, pp. 25-32, 2004.

[20] W. J. Rasdorf and O. Y. Abudayyeh, "Cost- and schedulecontrol integration: issues and needs," Journal of Construction Engineering and Management, vol. 117, no. 3, pp. 486-502, 1991.

[21] G. N. Rao and F. Grobler, "Integrated analyses of cost risk and schedule risk," in Proceedings of the 2nd Congress on Computing in Civil Engineering (ASCE '95), pp. 1404-1411, New York, NY, USA, June 1995.

[22] K. Kurihara and N. Nishiuchi, "Efficient Monte Carlo simulation method of GERT-type network for project management," Computers and Industrial Engineering, vol. 42, no. 2-4, pp. 521531, 2002.

[23] D. T. Phillips and A. A. B. Pritsker, "Gert network analysis of complex production systems," International Journal of Production Research, vol. 13, no. 3, pp. 223-227, 1975.

[24] B. W. Taylor and L. J. Moore, "R\&D project planning with QGERT network modeling and simulation," Management Science, vol. 26, no. 1, pp. 44-59, 1980. 


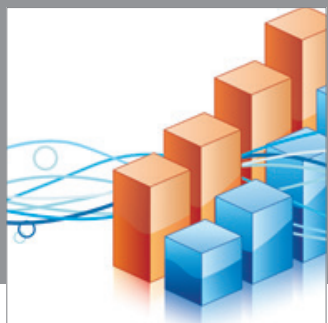

Advances in

Operations Research

mansans

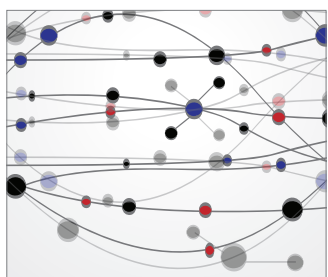

The Scientific World Journal
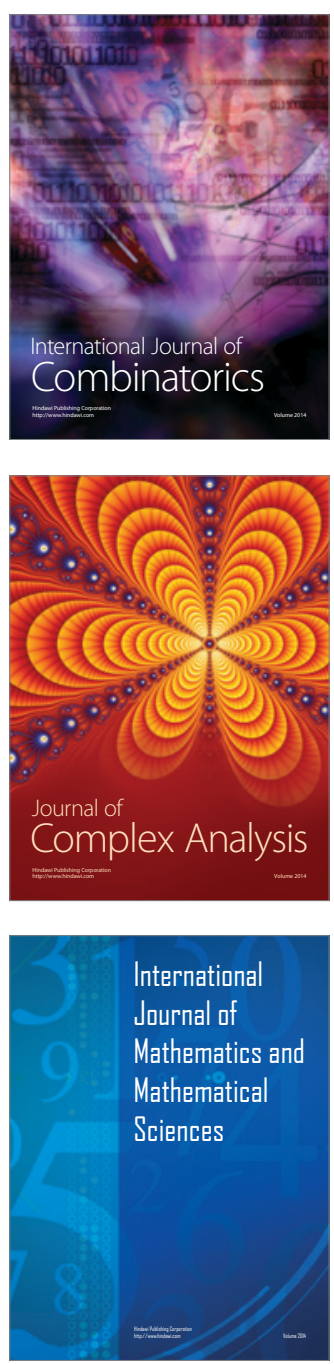
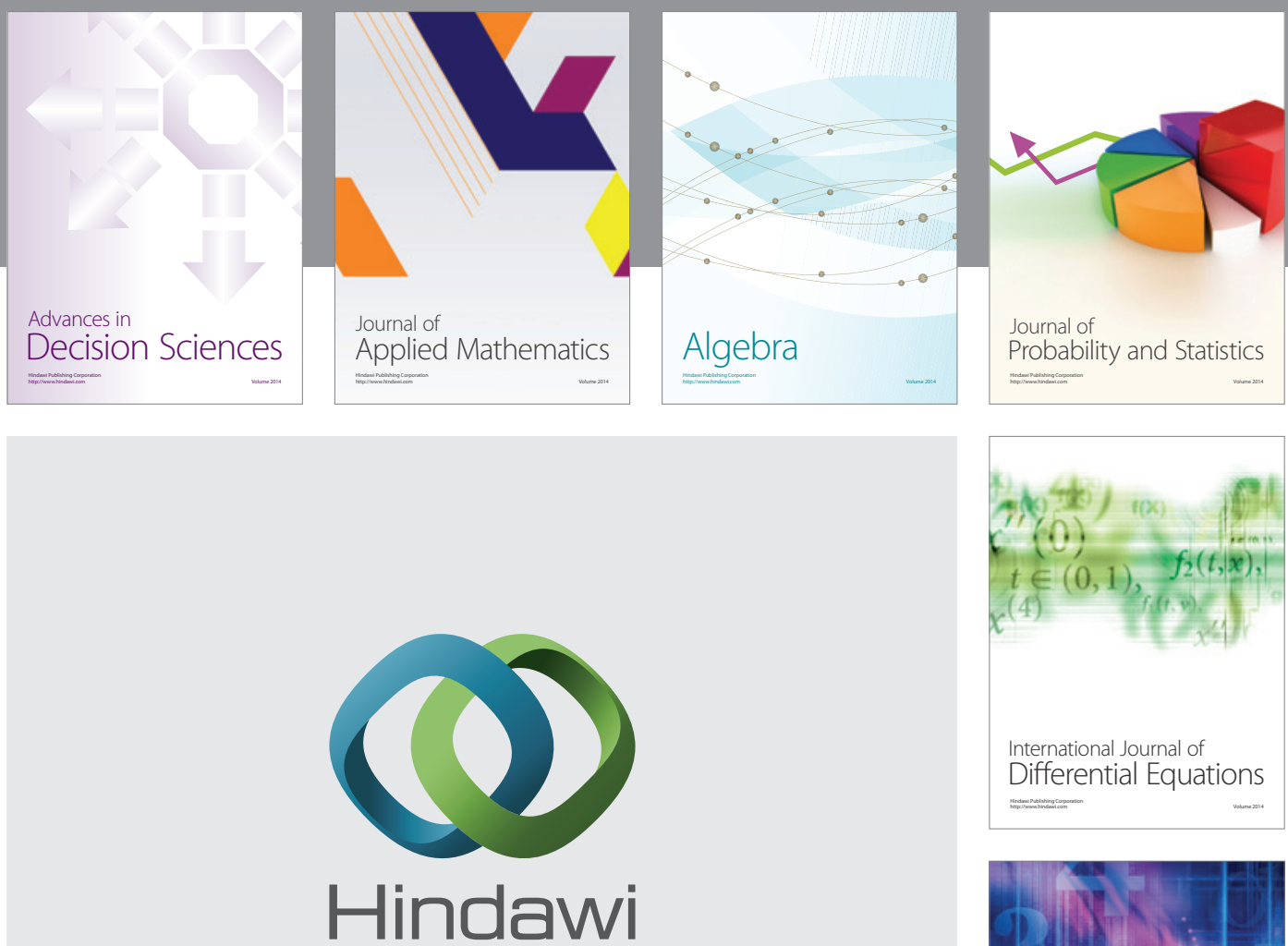

Submit your manuscripts at http://www.hindawi.com
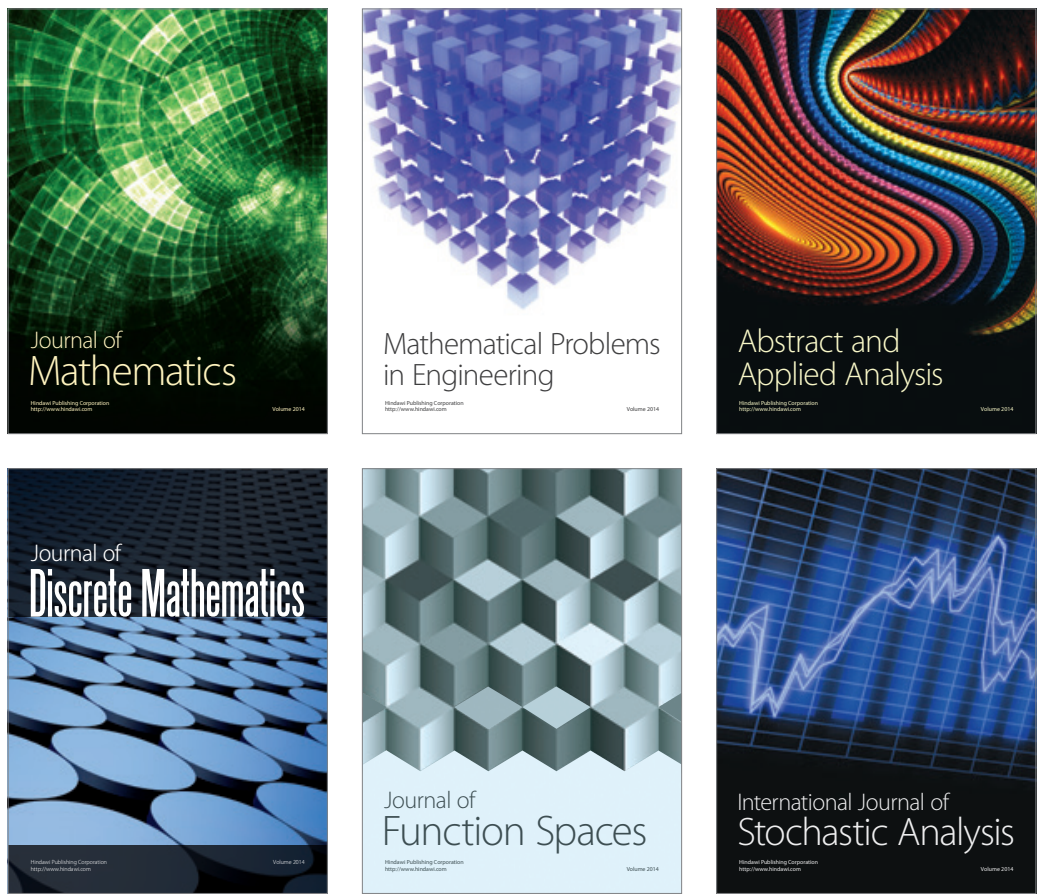

Journal of

Function Spaces

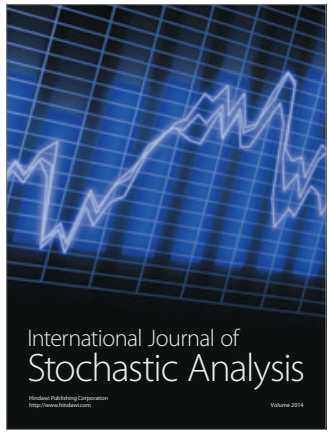

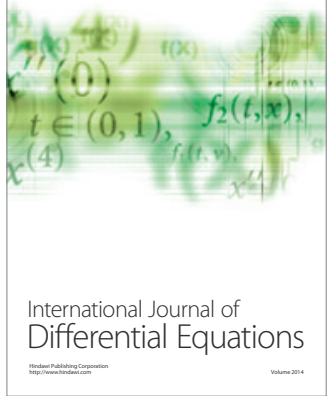
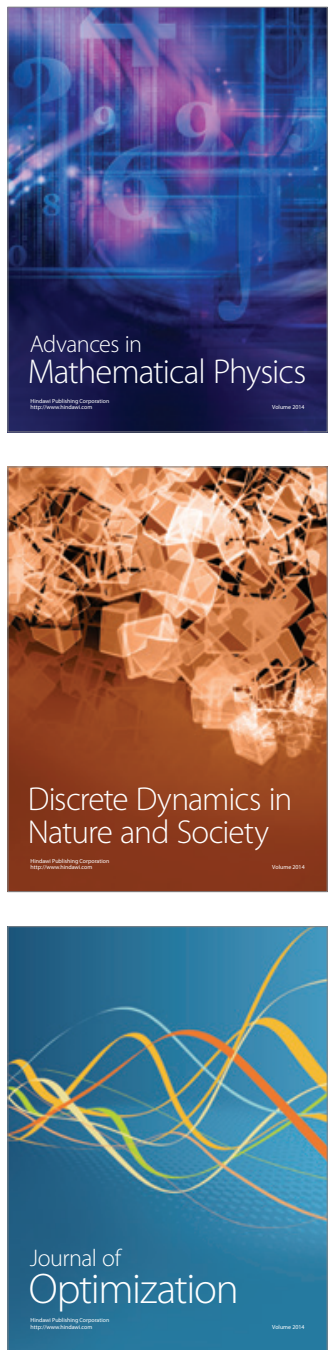